\title{
Studies on Written Corrective Feedback: Theoretical Perspectives, Empirical Evidence, and Future Directions
}

\author{
Ting Wang ${ }^{1} \&$ Lin Jiang ${ }^{1}$ \\ ${ }^{1}$ Faculty of English Language and Culture, Guangdong University of Foreign Studies, Guangzhou, Guangdong, \\ China \\ Correspondence: Ting Wang, Faculty of English Language and Culture, Guangdong University of Foreign \\ Studies, No. 2 North Baiyun Avenue, Guangzhou, Guangdong, China. Tel: 1-357-034-5953. E-mail: \\ gwwangting@139.com
}

Received: September 17, $2014 \quad$ Accepted: November 3, $2014 \quad$ Online Published: December 17, 2014
doi:10.5539/elt.v8n1p110 URL: http://dx.doi.org/10.5539/elt.v8n1p110

\begin{abstract}
The role of written corrective feedback (WCF) in the process of acquiring a second language (L2) has been an issue of considerable controversies over past decades. This article intends to provide a critical review of the increasing number of WCF studies thus far and to inspire new perspectives for future research. It starts by briefly tracing the theoretical positions on the role of WCF in L2 instruction. Subsequently, a synthesis of empirical arguments with respect to the effectiveness of WCF, the relative merits of various WCF options, and the amenability of different error categories to WCF are presented. Based on all the evidence, two common limitations: the focus on form-oriented WCF options and the narrow range of target errors are critically discussed in the final part. It concludes by suggesting that an integration between such learning enhancing variables as micro context and written feedback, and that an extension of target structure from learners' rule-governed errors to their non rule-governed errors should be investigated in future WCF studies so that fresh insights for WCF research could be achieved on one hand and pedagogical implications for L2 classroom instruction could be offered on the other.
\end{abstract}

Keywords: micro context, non rule-governed errors, second language acquisition, written corrective feedback

\section{Introduction}

Given the pervasiveness of linguistic errors in second language (L2) students' writing, teachers' written corrective feedback (WCF), also known as error correction or grammar correction, has long been a common practice in L2 instruction. In reality, L2 learners keep on making various errors despite their teachers' time-spending and efforts-paying feedback. Scholars like Truscott (1996) thus put forward their objections to error correction and even summoned its abandonment from L2 writing class, which received immediate attention and led to heated discussions on the part of L2 researchers.

For decades, a substantial body of empirical studies has been conducted to investigate the role of WCF in L2 writing and second language acquisition (SLA). Whereas L2 writing researchers often lay emphasis on the question of whether WCF helps L2 student writers to improve the overall effectiveness of their texts and to develop as more successful writers, SLA-oriented researchers seek to find out whether WCF facilitates long-term acquisition of particular linguistic features. Early L2 writing research on the efficacy of WCF has received severe criticisms due to their, as to be discussed later on, many methodological flaws. In contrast, SLA-oriented WCF research seems to be more carefully designed and tightly controlled by utilizing the pretest-treatment-posttest-delayed posttest structure. Nonetheless, it should be noted that both lines of research, with design and focus differences, have their own merits. Ferris (2010) thus suggested that, rather than competing with each other, L2 writing and SLA-oriented researchers can and should learn from each other's work and make collaborative efforts to bridge their methodological gap so that a broader understanding of the role of WCF in L2 learning can be achieved.

Although past decades have witnessed a proliferation of WCF studies, what these research efforts have shown as well as the possible implications for practice remain in dispute. In view of these unsettled disputes with respect to the role of WCF in L2 learning, this paper endeavors to contribute new insights to the current literature by first reviewing the theoretical arguments for and against the use of WCF in L2 instruction. It then moves to an 
overview of the empirical studies concerning the value of WCF in L2 learning. Finally, two widespread limitations in current WCF research are discussed, with new perspectives and directions proposed for future research efforts.

\section{Theoretical Perspectives on the Role of WCF in SLA}

In SLA research and theory, there has been disagreement over the decades about the role of WCF in language acquisition, with some arguing for its effectiveness in improving learners' writing accuracy whereas others claiming its ineffectiveness and even harmfulness, as to be discussed in the followings.

\subsection{Theoretical Foundations for WCF}

The rationale lending support for the positive role of WCF in L2 learning rests on various grounds. This section will summarize three recommended theoretical notions, namely, the Noticing Hypothesis, the Output Hypothesis, and the Interaction Hypothesis.

\subsubsection{WCF as a Noticing Facilitator}

The first theoretical argument supporting WCF is the Noticing Hypothesis. Schmidt (2001) stated that it is only through conscious attention that input can be converted into learners' intake and he further concluded that noticing is a prerequisite for language learning. Gass and Varonis (1994) likewise related the importance of noticing to the process of SLA by emphasizing that when learners are aware of the gap between what they can produce and what they need to produce, as well as between what they produce and what target language speakers produce, such an awareness would trigger a modification of their current interlanguage knowledge.

Given conscious attention to linguistic forms is considered facilitative to or even a prerequisite for L2 development, negative evidence such as WCF can thus be assumed to bring beneficial effects for SLA. By arousing learners' conscious attention to the correct linguistic forms, according to Gass (1997), error correction enables them to destabilize and restructure the part of their interlanguage that deviates from the target language, and ultimately promotes the process of SLA. It would seem, then, that WCF functions as a noticing facilitator that assists learners to bridge the gap between their interlanguage and the target language.

\subsubsection{WCF as an Output Monitor}

The second theoretical stance favorable to WCF is the Output Hypothesis. Swain (2005) acknowledged that learners' output enjoys great significance in the process of language acquisition in that output pushes learners to process language more deeply and with more mental effort than is necessary during listening and reading. With respect to the specific roles played by output, Swain reasonably identified three functions. The first one is the noticing function since output arouses learners to notice the gaps in their interlanguage system. Besides, it also has the function of hypothesis-testing by enabling learners to test hypotheses about linguistic correctness. Furthermore, output triggers learners' metalinguistic reflection which is conducive to their metalinguistic knowledge development on how L2 works.

In an attempt to further illustrate the roles acted by output, Swain (1991) warned that all the three functions cannot be realized by output alone with the recognition that if students are given insufficient feedback or no feedback regarding the extent to which their messages have been successfully conveyed, output may not play these roles at all. Given the widespread linguistic errors in L2 learners' output, teachers' WCF helps to facilitate the fulfillment of the "noticing" function with regard to the mismatch between learners' output and the target L2. Besides, the provided WCF may also lead learners to be able to tune themselves in for the accurate use of certain structures in their future output, thus enhancing their awareness of self-monitoring in L2 production. In short, WCF, as an output monitor, increases the chance of learners' correct output and thereafter promotes their L2 learning.

\subsubsection{WCF as an Interactive Input}

Interaction Hypothesis, advanced by Long (1996), construed the process of language acquisition as an interaction between internal and external factors. Whereas internal factors may be the language learning mechanism, external factors could be input either in the form of positive evidence (about what is acceptable in the target language) or negative evidence (about what is unacceptable in the target language). It has been pointed out that exposure to positive evidence alone is insufficient for language learning and that learners need negative evidence (e.g., corrective feedback) to produce modified output in oral interaction, thus highlighting the interactive input role of oral feedback in helping learners acquire the target forms.

Although the role of corrective feedback identified by the Interaction Hypothesis has been more frequently discussed in oral contexts than in written contexts, this does not mean that proposals arising form this context are 
irrelevant to the written context and the role of WCF in SLA (Bitchener, 2012). Ways in which theoretical constructs might also be extrapolated to the written context have been noted in several respects. First, learners can receive input from what they read as positive evidence and from teachers' WCF as negative evidence on their written output. The requirement of text revisions or new text writings offers learners the same chance to produce modified written output as in the case of oral interaction. Besides, conscious attention, similar to the oral context, is also indispensable in the written context if learners are to internalize the feedback. An advantage of WCF is that learners are provided with enough time to notice the feedback, which might not be the case in the oral context given the time constraints during on-line interactions. Furthermore, as it is proposed in oral interaction that individual factors may exert mediating effects on the uptake of feedback, individual differences would also have facilitative or inhibitive effects on learners' noticing and performance in the writing process. Taken together, conditions for language learning that can result from WCF seem to be similar to those arising from oral interaction, hence the interactive input role of WCF.

\subsection{Theoretical Objections against WCF}

While the aforementioned theoretical stances have made a stand for the use of WCF in L2 instruction, objections against error correction with regard to the problem of pseudolearning, learnability, and the potentially harmful side-effects of WCF have also been highlighted in literature.

\subsubsection{Problem of Pseudolearning}

The first position against the practice of WCF is that a simple information transfer like WCF could only lead to explicit knowledge, not to the implicit knowledge that is required for language acquisition (Truscott, 1996). Within the field of SLA, whereas implicit knowledge refers to the unconscious knowledge of a language that is non-verbalized, readily accessible during online language use, explicit knowledge refers to the conscious linguistic knowledge of grammatical rules and the appropriate meta-language for verbalizing this knowledge (Ellis, 2004). Currently, the assumption that implicit knowledge enables learners to communicate fluently has gained wide acceptance, while the value of explicit knowledge resulting from grammar instruction has been a controversial topic. Although some scholars (e.g., Ellis, 2005) maintain that explicit knowledge can be used in formulating utterances and monitoring language use, others (e.g., Krashen, 1982) presume its value to be very limited as it can only be used in monitoring when there is a focus on form.

Aside from the debate on the usefulness of explicit knowledge, views on the relationship between implicit and explicit knowledge have also been divergent. Some propose that the gap between the two types of knowledge can be gradually bridged by practice. Other linguists (e.g., Krashen, 1985) contend that the two systems can never interact through an interface. Based on the non-interface viewpoint, explicit knowledge resulted from the practice of WCF can never become the implicit knowledge that drives the actual language use, or, in Truscott's (1996) words, WCF will only lead to "pseudolearning" - described as "a superficial and possibly transient form of knowledge" (p. 345), thus negating the role of WCF in L2 instruction.

\subsubsection{Problem of Learnability}

The second theoretical objection advanced by Truscott (1996) against WCF relates to Pienemann's (1989) Learnability Hypothesis, which claimed that different grammatical features were acquired in a relatively strict order, and that learners can only acquire features for which they show developmental readiness. Linguistic structures that are beyond learners' stage of development will be unteachable since their internal learning mechanism cannot be steered to the instructional requirements.

Following this logic, Truscott deduced that if WCF provides learners with grammatical structures that they are not yet ready to acquire, no intake will occur at all. In order to produce any potentially positive effects, WCF should be provided in tune with a learner's current level of L2 development. Given the paucity of research findings on language developmental sequences thus far, developing a sequenced WCF methodology in practice might be impossible. Therefore, Truscott argued that WCF cannot be assumed to produce beneficial effects on L2 learning.

\subsubsection{Problem of Potentially Harmful Side-Effects}

Apart from claiming the ineffective role of WCF, Truscott (1996) further suggested that it could even be detrimental for the learning process. An inherent problem of WCF lies in triggering a high affective filter in learners, including increased anxiety and low self-esteem, which may discourage them from experimenting with the language and writing more in new tasks. Besides, WCF may further provoke learners' avoidance of using the structure that they have used awkwardly, resulting in their simplified writings that are lexically and structurally less complex. Moreover, the great amount of time spent on providing feedback diverts the attention of both the 
teacher and the students from other important activities, such as additional writing practice, which might be more likely to contribute to acquisition. Last but not least, doubt has also been cast onto L2 teachers' capacity in providing adequate and consistent WCF. Since most L2 teachers in EFL background are non-native speakers, if inappropriate judgment is made on learners' writing accuracy, harmful effects will naturally take place.

\section{Empirical Evidence on Written Corrective Feedback}

The various theoretical viewpoints on the role of WCF discussed above can only have validity if they are supported by research evidence. This section thus aims to provide a critical review of the empirical studies involving three heavily debated issues, which are (1) the general effectiveness of WCF, (2) the relative merits of various WCF types, and (3) the amenability of different errors categories to WCF.

\subsection{Whether WCF is Effective?}

Ever since Truscott's (1996) essay, increased interest has been inspired on the topic as to whether WCF can play a role in L2 acquisition. To answer this fundamentally significant question, a great deal of research has been done over past decades, with diversified results obtained.

Four of the early studies (Kepner, 1991; Robb, Ross, \& Shortreed, 1986; Semke, 1984; Sheppard, 1992) that intended to investigate the effectiveness of error correction in accuracy improvement failed to discover any statistical difference between the group that received WCF and the group that did not. This result, however, was seriously criticized for their methodology problems, and should thus be interpreted with caution when assessing the extent to which the studies provide clear evidence of the ineffectiveness of WCF. These studies set a "content-comments" group as a control group ( a group who did not receive error correction), which nonetheless cannot be regarded as a real control group because the provided "content comments" might be relevant to issues arising from learners' linguistic errors. This design problem has also plagued an array of other studies which claimed to have found positive effects for WCF (Chandler, 2003; Ferris, 1997, 2006; Ferris, Komura, Roberts, \& McKee, 2000; Lalande, 1982). Due to the lack of a non-feedback control group, learners' increased accuracy in these studies can not be attributed to the effects of WCF alone. At best, these accuracy improvements can only be interpreted as indicative of the potential that WCF might have. In short, neither the "no between-group difference" reported by early studies nor the "significant between-group difference" obtained by subsequent studies constituents a valid evidence against or for WCF. Findings from further research that manage to avoid the design flaw will have the final say.

The effectiveness of WCF has, again, been reported by some other studies (Ashwell, 2000; Fathman \& Whalley, 1990; Ferris \& Roberts, 2001), which, however, also suffered from another design problem. In these studies, evidence for accuracy development was merely based on learners' short-term improved performance in text revision, which sheds no light on whether these improvements would subsequently lead to the acquisition of correct forms in the long run. Thus, Truscott (2007) contended that WCF could only be considered as effective for revision but not as effective for learning. Results gained in further studies that avoided this design flaw by adding a new text writing in the final test could then be considered as reliable evidence on the efficacy of WCF.

Taking lessons from these and other problems in past WCF research, current studies are better designed and the majority of them have yielded positive results for WCF (Bitchener, 2008; Bitchener \& Knoch, 2009; Bitchener, Young, \& Cameron, 2005; Ellis, Sheen, Murakami, \& Takashima, 2008; Sheen, Wright, \& Moldawa, 2009). All of these studies employed a quasi-experimental design with a non- feedback control group for comparison and targeted the use of English article system. In addition, they all investigated not only short-term improvement in revisions but also accuracy gains on new pieces of writing. Notwithstanding their attempt to avoid those identified design flaws in the literature (e.g., the absence of a control group, the excluding of a new text writing), these studies were still criticized for their narrow research focus, namely, English articles, since the positive effects of WCF on this structure cannot be a predictor of its effectiveness on other linguistic domains.

Contrary to these positive findings for WCF, Truscott and Hsu's (2008) study, by comparing the texts of writers who received and did not receive WCF and by tracing their accuracy improvement over time, has reported opposite results. Significant effectiveness of WCF attained by most researchers failed to be found in this study, and even if any significant priorities of WCF was found in comparison to the control group in the immediate posttest, these beneficial effects could not be lasted for a long time. As for the reasons why learners in this study failed to achieve significant improvement in new text writing, several standpoints have been proposed. First, given the small number of errors made by the involved participants in the first piece of writing, Bruton (2009) questioned whether there was much room for further improvement. Besides, the fact that the EFL learners in this study were of limited motivation to use the feedback may also account for the absence of the positive effects of WCF (Ferris, 2003). Moreover, the method of underlining errors in WCF treatment could not ensure that 
learners' attention has been sufficiently aroused, hence the less priorities of WCF in this study.

Overall, the majority of WCF studies to date have made concerted efforts to demonstrate that WCF is in fact effective in helping L2 learners achieve improved accuracy, though with only limited target structures investigated. A body of well-designed studies are still needed so that other key questions as to be discussed can be well addressed.

\subsection{Which Method of WCF is Effective?}

Despite the call for more empirical evidence on the efficacy of WCF, many researchers, assuming the practice is beneficial for L2 learning, have proceeded to investigate the relative effectiveness of various WCF options. The following part reviews the two dichotomies that have been receiving the lion's share of researchers' attention: the comparison between direct and indirect WCF and the contrast between focused and unfocused WCF.

\subsubsection{Direct vs. Indirect WCF}

The direct-indirect dichotomy is distinguished by the explicitness of WCF when it is provided. Direct WCF is defined as the direct provision of the correct linguistic forms by the teacher to the student above the linguistic error whereas indirect WCF only indicates that in some way an error has been made without explicit correction (Ferris, 2003). Both types of feedback come in a variety of specific forms. Direct WCF often includes the crossing out of an unnecessary word, insertion of a missing word, and written metalinguistic information introducing grammatical rules, while indirect WCF usually involves the underlining or circling of an error, recording in the margin the number of errors in a given line, and coding of errors to show the error places or categories (Bitchener, 2009). An important question thus arises as to which type of WCF is more effective for accuracy improvement. Over the years, a great deal of research has been done, with conflicting results obtained.

Although two early studies by Robb et al. (1986) and Semke (1984), with 134 EFL learners and 141 FL learners, failed to discover any significant difference between direct and indirect WCF, Lalande's (1982) study of 60 German intermediate learners reported an advantage for indirect WCF over direct WCF, but the observed between-group difference was not statistically significant. In a similar vein, Ferris and Helt's (2000) study of 92 learners also found that the effects of indirect WCF was superior to direct error correction. In light of these results, L2 writing researchers argue for the importance of indirect feedback as a means to involve learners in guided problem-solving and to encourage them to take more responsibility for their own progress. Besides, they also maintained that indirect WCF could yield more beneficial results than direct WCF for it requires learners to engage themselves in a more profound form of language processing by promoting self-reflection, attention, and noticing, which ultimately helps to foster long term acquisition (Ferris \& Roberts, 2001)

On the other hand, recent SLA-focused studies on WCF have obtained contrasted results. Chandler's (2003) study of 31 ESL learners showed an advantage for direct over indirect WCF, though the difference with one of the indirect WCF types (i.e., underlining) was nonsignificant. Similarly, both Van Beuningen, Jong, and Kuiken's (2008) study of secondary school learners and Bitchener and Knoch's (2010) study of advanced ESL learners found that, even though both direct and indirect feedback had a significant positive short-term effects on participants' accuracy performance, direct written feedback had a more significant long-term effect than indirect WCF. In view of these findings, SLA-focused researchers argue for the superiority of direct WCF by contending that (1) it reduces learners' confusion as to whether they can understand or remember the provided feedback; (2) it supplies learners with more explicit information on how to grapple with such complex error types as syntactic structure and idiomatic usage; (3) it offers learners the immediate feedback that is needed for testing hypothesis about the use of the target language.

All the above conflicting conclusions gained by L2 writing and SLA researchers might be attributed to their differences in research focus (Ferris, 2010). In the case of tracing evidence for the mastery over a specific structure, direct WCF provides the most efficient information, while in the case of evaluating the success of possible strategies for effective metacognitive skills, indirect WCF that requires more learners' effort may be better. On balance, extant WCF research fails to come to any firm conclusions regarding the relative merits between direct and indirect WCF and further research is thus needed.

\subsubsection{Focused vs. Unfocused WCF}

The other dichotomy in WCF literature is that between focused and unfocused WCF. Whereas focused WCF targets only one or a few linguistic error types, unfocused WCF involves the correction of a broad range of error categories that appear in learners' texts. To date, research into the relative effectiveness of the two approaches has also obtained differing findings.

A growing range of rigorously designed SLA studies have reported positive effects of focused WCF. Bitchener's 
(2008) study investigated the effects of focused WCF on the development of 75 low intermediate ESL learners' performance on the use of English article system. It found that the accuracy of those who received focused feedback in the immediate posttest outperformed those in the non- feedback control group and that this level of accuracy improvement could be retained two months later. This study was later on extended into Bitchener and Knoch's (2008) study of 144 learners, which likewise found a significant priority of focused WCF. Keeping the same targeted focus (English articles) but expanding the investigation into a group of higher proficiency learners, Bitchener and Knoch's (2010) study of 63 ESL learners, again, reported the effectiveness of focused WCF on both the immediate and delayed posttest. Further findings in support of focused WCF can still be found in studies by Sheen (2007), Sheen et al. (2009). Considering all these evidence, SLA researchers contend that focused WCF is more helpful because it is more likely to trigger learners' attention by targeting at a specific error type and that it also grants a bigger chance for learners to restructure their interlanguage systems as they receive repeated evidence of how to correct the same error (Shintani, Ellis, \& Suzuki, 2014). In addition, the greater potential of focused WCF to impact accuracy development is self-evident since unfocused WCF may impose cognitive overload when a wide range of errors are targeted at the same time.

Compared to the robust research base on focused WCF, there is a severe paucity of studies into the effectiveness of unfocused WCF on L2 learning. Four early L2 writing studies (Kepner, 1991; Robb et al., 1986; Semke, 1984; Sheppard, 1992) that sought to explore the learning potential of WCF on learners' comprehensive error categories found no statistical benefits of unfocused WCF in comparison to the comments-on-content group. This result, however, should be interpreted with caution due to their design flaw (i.e., the absence of a strictly control group). Contrary to the findings of early unfocused WCF studies, Van Beuningen et al.'s (2008) study has reported an advantage for unfocused WCF over non-feedback control group on the immediate posttest. This result provides empirical support for the priorities of unfocused WCF as identified by L2 writing researchers that (1) correction on unfocused errors corresponds to the actual teaching practice; (2) learners may also have less confusion as regards why some of their errors are corrected whereas others are not; (3) even though unfocused WCF is of less priorities in assisting learners to acquire a specific feature in the short term, it may be superior in the long run by addressing a broad range of errors (Storch \& Wigglesworth, 2010).

To date, only two studies investigated the relative effectiveness of focused and unfocused WCF within a single study design. Ellis et al.'s (2008) study failed to find any differences in accuracy gains between the focused and unfocused WCF groups, which, however, were questioned for the unequal amount of feedback provided to the two groups. Although Sheen et al.'s (2009) study reported that focused feedback produced more benefits than unfocused feedback, the feedback provided to the unfocused group was rather unsystematic, with some errors corrected while others ignored. Thus, the question of whether focused or unfocused WCF is more effective in helping learners acquire L2 structures cannot, at this stage, be fully answered.

In view of this mixed situation, further efforts may devote to the exploration of a middle position where focused WCF is still provided but in ways that are more representative of the diversity and complexity of error categories in learners' writing (Ferris, 2010). In other words, the problem of whether focused or unfocused WCF is more effective will only be well resolved if it is examined together with other questions, such as the interaction between WCF types and error categories.

\subsection{Which Error Category is Amenable to WCF?}

Truscott's (1996) argument that no single form of correction can be presumed to help learners acquire knowledge of all linguistic domains has raised another important issue as to which errors to correct and which not. In response, Ferris (1999) made a distinction between treatable and untreatable errors, which were subsequently termed as rule-governed and non rule-governed errors by Van Beuningen (2011). With regard to rule-governed (i.e., treatable) errors, learners can conduct self-correction by referring to a grammar book. Errors in article usage, verb tense, and subject-verb agreement are good examples of errors that can be corrected by a clear cut rule. With regard to non rule-governed (i.e., untreatable) errors, learners need to rely on their acquired knowledge of the target language to be able to correct them. Good examples of non rule-governed errors are errors in prepositions, collocations, and word choice.

At present, a large number of studies that investigated the efficacy of WCF have been intensively circumscribed to a narrow set of rule-governed structures. As mentioned previously, the majority of the SLA-oriented studies that show evidence for the positive role of WCF have focused on English articles, thus implications that can be drawn from these studies are rather restricted as $\mathrm{Xu}$ (2009) argued that this narrow research focus did not offer any idea of how students' control over other linguistic structures might be affected by the treatment. It was suggested that future studies should be conducted to examine the effect of WCF on other problematic categories 
(Ellis et al., 2008; Sheen et al., 2009).

To echo this plea, several studies have made a start on this agenda. Bitchener et al. (2005) examined how different kinds of feedback affected learners' accuracy development on three structures (i.e., simple past tense, articles, and prepositions) and reported gains in accuracy for both past tense and articles, but not for prepositions. They argued that past tense and articles are patterned and rule- governed problems while prepositions are more idiosyncratic in nature, which supported the view that feedback would be most likely to be successful when directed at rule-governed, treatable errors, and that rule-governed, untreatable errors are less amenable to feedback (Ferris, 1999). However, Kassim and Ng's (2014) study found that prepositions were actually susceptible to WCF and that the treatment effects can be retained for a long time. This study, together with several other studies to be discussed later on, thus challenged the view that non rule-governed errors are untreatable.

Shintani et al. (2014) compared the effectiveness of WCF on two very different grammatical structures (i.e., hypothetical conditional and articles) and found that feedback resulted in improved accuracy for hypothetical conditional but not for articles. Such a result sheds new light to the current literature in two ways. First, it found that learners are more attentive to the feedback on the structure that is more salient and semantically functional since the hypothetical conditional received more attention than articles. Second, the distinction between treatable and untreatable errors is proved to be problematic because the effects of WCF on different structures might vary not just in terms of whether they are rule-based or not but also in their complexity.

Instead of examining the influences of WCF on one or a few linguistic error types, Van Beuningen, Jong, and Kuiken (2012) studied the curability of both rule-governed errors (e.g., morphological and syntactic errors) and non rule-governed errors (e.g., orthographical and lexical errors). Results revealed that both error categories were amenable to WCF, and that rule-based errors were more amenable to direct WCF whereas indirect WCF was more effective for non rule-based errors. Such a result not only posed a challenge to the distinction between treatable and untreatable errors, but also questioned the hypothesis that rule-governed errors are better treated with indirect correction while direct correction is preferable for non-rule governed errors (Ferris, 1999).

To sum, despite the increasing number of studies into the relationship between WCF and accuracy development, a mixed situation with respect to the relative effectiveness of different WCF options still exist. Besides, current research base has been restricted to investigating the effectiveness of WCF on certain rule-governed features, with learners' non rule-governed errors almost left untouched upon. Therefore, fresh perspectives and insights need to be injected into future research design so that new accomplishments on these concerned issues could be achieved.

\section{Directions for Future Studies}

With these issues in mind - the preferred WCF option and the insufficient consideration on learners' non rule-governed errors - this section seeks to propose some suggestions and directions for future studies by highlighting changes on two widespread limitations in current research. One is the change on form-oriented WCF options by including some micro contextual variables; and the other is the extension of targeted errors from rule-governed categories to non rule-governed ones.

\subsection{Change on Form-Oriented WCF Options}

As discussed previously, many studies that examined the relative effectiveness of direct and indirect WCF have been concerned about whether certain individual types or combinations of different types are more effective than others. In essence, these studies have laid too much emphasis on whether the difference in the forms of WCF will lead to any significantly different influences on learners' accuracy improvement but rather less on how to draw on some language learning enhancing variables. As a result, the value of WCF has not been well unearthed thus far.

As one of such learning mediating factors, contextual variables are now gaining wide recognition and emphasis due to a convergence of theoretical and empirical insights. On the theoretical side, usage- based models suggest that the fabric of the contexts in which linguistic development takes place is profoundly interwoven with that development and deserves minute attention (Ellis \& Larsen-Freeman, 2009; Eskildsen, 2009). On the empirical side, a number of studies have found that context-embedded stimuli are superior to context-reduced stimuli in helping learners acquire language by engaging them with different levels of cognitive system (Shepard, 1967; Snodgrass, Volvovitz, \& Walfish, 1972). Despite these established benefits of context in the process of L2 learning, an examination of the potential influence of contextual factors on learners' engagement with WCF has not been prominent in the literature. Admittedly, some attention has been allocated to such macro contexts as 
learners' educational background (Bitchener \& Knoch, 2008), little consideration has been given to micro contexts where factors specifically related to the ways of providing feedback (e.g. context-embedded WCF) might impact upon learners' engagement with and their uptake of the provided WCF.

In what ways, then, can these micro contexts be operationalized? Findings from the field of recall and retention may have shed new light to the research into the notoriously complex concept of "context". McBirde and Dosher's (2002) study compared the effects of two different kinds of stimuli-context-reduced stimuli (i.e., a single word) and context-embedded stimuli (i.e., the combination of a word with its pictorial illustration) on vocabulary retention. It found that the presentation of verbal and pictorial materials improves learners' word memorization over the presentation of a single verbal cue. It can be deduced that illustrative pictures, as a possible way of enriching the micro contexts of linguistic materials (Prince, 1996), may likewise exert beneficial effects on learners' mastery over target forms if it was embedded in teachers' written feedback. Compared with form-oriented WCF, context-embedded WCF (i.e., correct forms coupled with colored pictures) requires learners to access not only a verbal code but also an image code, thus deepening their level of processing and presumably fostering their L2 acquisition. Apart from illustrative pictures, other possible ways, such as one-on-one conferences or mini-lessons to small groups of learners, may also help to enrich the micro context of the provided WCF to such an extent that learners can be actively involved in the process of internalizing feedback. Future empirical studies that aim to investigate the extent to which these and other micro contextual variables can enhance the efficiency of WCF are strongly appealed for so that new implications for L2 teaching practice could be gained (Bitchener \& Ferris, 2012).

\subsection{Extension of Target Structures}

As mentioned above, while there is a robust research base on the efficacy of WCF on rule-governed errors, there is far more limited research base on the extent to which WCF can play a role in the acquisition of non rule-governed structures. Such a research bias may be related to the suggestion that WCF should be directed to errors which are deemed treatable and that idiosyncratic errors are less suitable targets for WCF (Ferris, 1999), which, however, was proved to be dubious and groundless by an increasing number of studies (e.g., Shintani et al., 2014; Van Beuningen et al., 2012). Clearly, there is a need for more empirical evidence to arrive at a fuller understanding of what constitutes a "treatable" or an "untreatable" error.

As one common type of non rule-governed structures, collocations are often used awkwardly by L2 learners. However, no study to date has pioneered the investigation into the efficacy of WCF on L2 learners' collocation errors. Studies in this line are considered to be quite necessary due to a number of respects. First, an efficient way in tackling learners' collocation problems remains undiscovered. Collocation knowledge is considered to be of central importance to fluent and idiomatic language use (Wray, 2005), nevertheless, the deviant use of collocations is widespread in L2 learners' language output due to an array of factors, such as literal translation, ignorance of rule restrictions, and the overliberal assumptions about the collocation equivalence of synonyms (Lewis, 2000). Confronted with these errors, teachers use direct corrective feedback most of the time, though its effectiveness on students' accuracy improvement remains unestablished. Second, most collocation studies have been descriptive in nature, often analyzing either the division of error categories or possible reasons for these errors, with little research into how the errors can be grappled with. Furthermore, the label of a potentially untreatable error type attached to collocation errors (Ferris, 2006) also calls for future studies to find out whether WCF can be helpful. On balance, in order to understand the full potential of WCF for L2 acquisition, future WCF studies need to target such idiosyncratic, non rule-based structure as collocations.

\section{Conclusion}

In accordance with the theoretical foundations underlying the use of WCF in L2 instruction, many empirical studies have provided positive evidence on the effectiveness of WCF. However, a definite conclusion as regards the relative value of different WCF options as well as the amenability of various error categories to WCF is still hard to draw due to the obtained mixed results and several lingering concerns in current research design. First, all the available WCF options designed in present studies are restricted to the alternations on the forms of feedback, with cursory concern on the nature of language acquisition itself. And second many of the present studies only focused on several patterned and rule-governed errors, especially the use of English articles, it is thus difficult to generalize the obtained conclusions to other linguistic features within the scope of SLA. Now is the time that the research community puts the narrowly form-oriented WCF investigation to rest and turns its attention to the integration between WCF and some micro contextual variables in language learning, such as colored pictures that helps to promote learners' interactive engagement with WCF treatment. Besides, future studies could investigate whether WCF enjoys any value for some non rule-governed structures, which have 
found to be frequently erred but enjoy great significance in learners' use of language, such as collocation problems, since the extant research has not shed much light on this issue. By doing so, it is hoped that the value of WCF in L2 instruction can be investigated from perspectives across the board, and that pedagogical implications on how to provide efficient WCF in tackling L2 learners' overall linguistic errors could be achieved.

\section{Acknowledgements}

We are deeply grateful to the anonymous reviewers for their valuable feedback. This research was supported by a grant from the China National Social Science Foundation (14CYY018), an MOE project (12JJD740006) of the Center for Linguistics and Applied Linguistics, Guangdong University of Foreign Studies, a Guangdong High-level Personnel Project (312-GK131036), a Guangdong Higher Education Reform Project (GDJG20141098), and a Postgraduate Research Innovation Project attached to Guangdong University of Foreign Studies (14GWCXXM-01).

\section{References}

Ashwell, T. (2000). Patterns of teacher response to student writing in a multiple-draft composition classroom: Is content feedback followed by form feedback the best method? Journal of Second Language Writing, 9 , 227-257. http://dx.doi.org/10.1016/S1060-3743(00)00027-8

Bitchener, J. (2008). Evidence in support of written corrective feedback. Journal of Second Language Writing, 17 , 102-118. http://dx.doi.org/10.1016/j.jslw.2007.11.004

Bitchener, J. (2009). Measuring the effectiveness of written corrective feedback: A response to "Overgeneralization from a narrow focus: A response to Bitchener (2008)". Journal of Second Language Writing, 18, 276-279. http://dx.doi.org/10.1016/j.jslw.2009.06.001

Bitchener, J. (2012). A reflection on 'the language learning potential' of written CF. Journal of Second Language Writing, 21, 348-363. http://dx.doi.org/10.1016/j.jslw.2012.09.006

Bitchener, J., \& Ferris, D. R. (2012). Written corrective feedback in second language acquisition and writing. New York: Routledge.

Bitchener, J., \& Knoch, U. (2008). The value of written corrective feedback for migrant and international students. Language Teaching Research, 12, 409-431. http://dx.doi.org/10.1177/1362168808089924

Bitchener, J., \& Knoch, U. (2009). The value of a focused approach to written corrective feedback. ELT journal, 63, 204-211. http://dx.doi.org/10.1093/elt/ccn043

Bitchener, J., \& Knoch, U. (2010). The contribution of written corrective feedback to language development: A ten month investigation. Applied Linguistics, 31, 193-214. http://dx.doi.org/10.1093/applin/amp016

Bitchener, J., Young, S., \& Cameron, D. (2005). The effect of different types of corrective feedback on ESL student writing. Journal of Second Language Writing, 14, 191-205. http://dx.doi.org/10.1016/j.jslw.2005.08.001

Bruton, A. (2009). Designing research into the effects of grammar correction in L2 writing: Not so

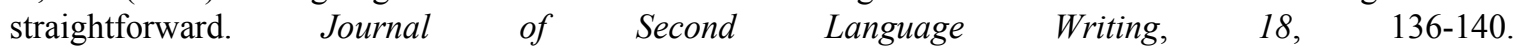
http://dx.doi.org/10.1016/j.jslw.2009.02.005

Chandler, J. (2003). The efficacy of various kinds of error feedback for improvement in the accuracy and fluency of L2 student writing. Journal of Second Language Writing, 12, 267-296. http://dx.doi.org/10.1016/S1060-3743(03)00038-9

Ellis, N. C., \& Larsen-Freeman, D. (2009). Constructing a second language: Analyses and computational simulations of the emergence of linguistic constructions from usage. Language Learning, 59, 90-125. http://dx.doi.org/10.1111/j.1467-9922.2009.00537.x

Ellis, R. (2004). The definition and measurement of L2 explicit knowledge. Language learning, 54, 227-275. http://dx.doi.org/10.1111/j.1467-9922.2004.00255.x

Ellis, R. (2005). Principles of instructed language learning. System, 33, 209-224. http://dx.doi.org/10.1016/j.system.2004.12.006

Ellis, R., Sheen, Y., Murakami, M., \& Takashima, H. (2008). The effects of focused and unfocused written corrective feedback in an English as a foreign language context. System, 36, 353-371. http://dx.doi.org/10.1016/j.system.2008.02.001

Eskildsen, S. W. (2009). Constructing another language: Usage-based linguistics in second language acquisition. 
Applied Linguistics, 30, 335-357. http://dx.doi.org/10.1093/applin/amn037

Fathman, A., \& Whalley, E. (1990). Teacher response to student writing: Focus on form versus content. In B. Kroll (Ed.), Second language writing: Research insights for the classroom (pp. 178-190). Cambridge: Cambridge University Press. http://dx.doi.org/10.1017/CBO9781139524551.016

Ferris, D. R. (1997). The influence of teacher commentary on student revision. TESOL Quarterly, 31, 315-339. http://dx.doi.org/10.2307/3588049

Ferris, D. R. (1999). The case for grammar correction in L2 writing classes: A response to Truscott (1996). Journal of Second Language Writing, 8, 1-11. http://dx.doi.org/10.1016/S1060-3743(99)80110-6

Ferris, D. R. (2003). Response to student writing: Implications for second language students. New York: Routledge.

Ferris, D. R. (2006). Does error feedback help student writers? New evidence on the short- and long-term effects of written error correction. In K. Hyland, \& F. Hyland (Eds.), Feedback in second language writing: Contexts and issues (pp. 81-104). Cambridge: Cambridge University Press.

Ferris, D. R. (2010). Second language writing research and writing corrective feedback in SLA. Studies in Second Language Acquisition, 32, 181-201. http://dx.doi.org/ 10.1017/S0272263109990490

Ferris, D. R., Chaney, S. J., Komura, K., Roberts, B. J., \& McKee, S. (2000, March). Perspectives, problems, \& practices in treating written error (pp. 14-18). Colloquium presented at the International TESOL Convention.

Ferris, D. R., \& Helt, M. (2000, March). Was Truscott right? New evidence on the effects of error correction in L2 writing classes. Paper presented at the AAAL Conference, Vancouver, BC.

Ferris, D. R., \& Roberts, B. (2001). Error feedback in L2 writing classes: How explicit does it need to be? Journal of Second Language Writing, 10, 161-184. http://dx.doi.org/10.1016/S1060-3743(01)00039-X

Gass, S. M. (1997). Input, interaction, and the second language learner. New York: Routledge.

Gass, S. M., \& Varonis, E. M. (1994). Input, interaction, and second language production. Studies in Second Language Acquisition, 16, 283-302. http://dx.doi.org/10.1017/S0272263100013097

Kassim, A., \& Ng, L. L. (2014). Investigating the Efficacy of Focused and Unfocused Corrective Feedback on the Accurate Use of Prepositions in Written Work. English Language Teaching, 7, 119-130. http://dx.doi.org/10.5539/elt.v7n2p119

Kepner, C. G. (1991). An experiment in the relationship of types of written feedback to the development of second-language writing skills. The Modern Language Journal, 7, 305-313. http://dx.doi.org/10.1111/j.1540-4781.1991.tb05359.x

Krashen, S. D. (1982). Principles and practice in second language acquisition. Pergamon: Oxford.

Krashen, S. D. (1985). The input hypothesis: Issues and implications. London: Longman.

Lalande, J. F. (1982). Reducing composition errors: an experiment. The Modern Language Journal, 66, 140-149. http://dx.doi.org/ 10.1111/j.1540-4781.1982.tb06973.x

Lewis, M. (2000). Teaching collocation: Further developments in the lexical approach. Hove: Language Teaching Publications.

Long, M. H. (1996). The role of the linguistic environment in second language acquisition. In W. C. Richie, \& B. K. Bahtia (Eds.), Handbook of second language acquisition (pp. 413-468). New York: Academic Press.

McBirde, D. M., \& Dosher, B. A. (2002). A comparison of conscious and automatic memory processes for picture and word stimuli: A process dissociation analysis. Consciousness and Cognition, 11, 423-460. http://dx.doi.org/10.1016/S1053-8100(02)00007-7

Pienemann, M. (1989). Is language teachable? Psycholinguistic experiments and hypotheses. Applied linguistics, 10, 52-79. http://dx.doi.org/10.1093/applin/10.1.52

Robb, T., Ross, S., \& Shortreed, I. (1986). Salience of feedback on error and its effect on EFL writing quality. TESOL Quarterly, 20, 83-95. http://dx.doi.org/10.2307/3586390

Prince, P. (1996). Second language vocabulary learning: The role of context versus translations as a function of $\begin{array}{lllll}\text { proficiency. The } & \text { Modern }\end{array}$ http://dx.doi.org/10.1111/j.1540-4781.1996.tb05468.x

Schmidt, R. (2001). Attention. In P. Robinson (Ed.), Cognition and Second Language Instruction (pp. 3-32). 
New York: Cambridge University Press.

Semke, H. D. (1984). Effects of the red pen. Foreign Language Annals, 17, 195-202. http://dx.doi.org/10.1111/j.1944-9720.1984.tb01727.x

Sheen, Y. (2007). The effect of focused written corrective feedback and language aptitude on ESL learners' $\begin{array}{lllll}\text { acquisition of } & \text { articles. }\end{array}$ http://dx.doi.org/10.1002/j.1545-7249.2007.tb00059.x

Sheen, Y., Wright, D., \& Moldawa, A. (2009). Differential effects of focused and unfocused written correction on the accurate use of grammatical forms by adult ESL learners. System, 37, 556-569. http://dx.doi.org/10.1016/j.system.2009.09.002

Shepard, R. N. (1967). Recognition memory for words, sentences, and pictures. Journal of verbal Learning and verbal Behavior, 6, 156-163. http://dx.doi.org/10.1016/S0022-5371(67)80067-7

Sheppard, K. (1992). Two feedback types: Do they make a difference? RELC journal, 23, 103-110. http://dx.doi.org/10.1177/003368829202300107

Shintani, N., Ellis, R., \& Suzuki, W. (2014). Effects of Written Feedback and Revision on Learners' Accuracy in Using Two English Grammatical Structures. Language Learning, 64, 103-131. http://dx.doi.org/10.1111/lang.12029

Snodgrass, J. G., Volvovitz, R., \& Walfish, E. R. (1972). Recognition memory for words, pictures, and words+pictures. Psychonomic Science, 27, 345-347. http://dx.doi.org/10.3758/BF03328986

Storch, N., \& Wigglesworth, G. (2010). Learners' processing, uptake and retention of corrective feedback on

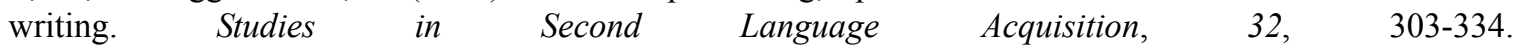
http://dx.doi.org/10.1017/S0272263109990532

Swain, M. (1991). French immersion and its offshoots: Getting two for one. In B. Freed (Ed.), Foreign language acquisition: Research and the classroom (pp. 91-103). Lexington, MA: Heath.

Swain, M. (2005). The output hypothesis: Theory and research. In E. Hinkel (Ed.), Handbook of Research in Second Language Teaching and Learning (pp. 471-484). New Jersey: Lawrence Erlbaum Associates.

Truscott, J. (1996). The case against grammar correction in L2 writing classes. Language Learning, 46, 327-369. http://dx.doi.org/ 10.1111/j.1467-1770.1996.tb01238.x

Truscott, J. (2007). The effect of error correction on learners' ability to write accurately. Journal of second language Writing, 16, 255-272. http://dx.doi.org/10.1016/j.jslw.2007.06.003

Truscott, J., \& Hsu, A. Y. (2008). Error correction, revision, and learning. Journal of Second Language Writing, 17, 292-305. http://dx.doi.org/10.1016/j.jslw.2008.05.003

Van Beuningen, C. G. (2011). The effectiveness of comprehensive corrective feedback in Second language writing. Oisterwijk: Uitgeverij BOXPress.

Van Beuningen, C. G., De Jong, N. H., \& Kuiken, F. (2008). The effect of direct and indirect corrective feedback on L2 learners' written accuracy. ITL-International Journal of Applied Linguistics, 156, 279-296. http://dx.doi.org/10.2143/ITL.156.0.2034439

Van Beuningen, C. G., De Jong, N. H., \& Kuiken, F. (2012). Evidence on the effectiveness of comprehensive error correction in second language writing. Language Learning, 62, 1-41. http://dx.doi.org/10.1111/j.1467-9922.2011.00674.x

Wray, A. (2005). Formulaic language and the lexicon. Cambridge University Press.

Xu, C. Q. (2009). Overgeneralization from a narrow focus: A response to Ellis et al. (2008) and Bitchener (2008). Journal of Second Language Writing, 18, 270-275. http://dx.doi.org/10.1016/j.jslw.2009.05.005

\section{Copyrights}

Copyright for this article is retained by the author(s), with first publication rights granted to the journal.

This is an open-access article distributed under the terms and conditions of the Creative Commons Attribution license (http://creativecommons.org/licenses/by/3.0/). 